\title{
Obesity Education in Medical School Curricula in Korea
}

\author{
Sang Yeoup Lee* \\ Family Medicine Clinic and Research Institute of Convergence of Biomedical Science and Technology, Pusan National University Yangsan Hospital, Yangsan; \\ Department of Medical Education, Pusan National University School of Medicine, Yangsan, Korea
}

Obesity is one of the three most common diseases, affecting about one-third of adults. Obesity also increases vulnerability to metabolic disorders, psychological disorders, and various cancers and decreases quality of life. Therefore, obesity must be adequately addressed in medical school. Here, I will review how obesity education is implemented in medical school curricula in Korea. Many studies have shown that students who are well educated about obesity through various educational methods reduce their prejudice toward obese patients. The Korean Society for the Study of Obesity is an interdisciplinary academy, including experts from fields such as general research, clinical practice, nutrition, nursing, exercise, and rehabilitation. They aim to identify the core competencies of obesity education necessary for medical students, develop curricula of obesity education, and present examples of lectures and discussions. In the future, health professionals who receive such education will be able to take better care of obese patients without bias.

Key words: Medical schools, Medical students, Obesity, Education, Curriculum
Received October 30, 2017

Reviewed November 15, 2017

Accepted December 7, 2017

${ }^{*}$ Corresponding author

Sang Yeoup Lee

(i)

https://orcid.org/0000-0002-3585-9910

Department of Medical Education, Pusan National University School of Medicine, 49 Busandaehak-ro, Mulgeum-eup, Yangsan 50612, Korea Tel: +82-51-510-8024

Fax: +82-51-510-8125

E-mail: saylee@pnu.edu

\section{INTRODUCTION}

The prevalence of obese adults (body mass index, $\geq 25 \mathrm{~kg} / \mathrm{m}^{2}$ ) in Korea was 32.4\%, according to the 2015 Korea National Health and Nutrition Examination Survey. Using the definition of abdominal obesity from the Korean Society for the Study of Obesity (KSSO), the prevalence of abdominal obesity was $20.8 \%$ in $2015 .{ }^{1}$ Obesity is one of the most common diseases in adults, especially during middle age, occurring in one out of every 1,000 people. In addition, hypertension, type 2 diabetes, dyslipidemia, myocardial infarction, ischemic stroke, musculoskeletal disorders, and even various cancers are commonly accompanied by obesity. Obesity also increases vulnerability to psychological disorders and decreases quality of life. ${ }^{2}$ Without accepting obesity as a disease that can occur at any time, even to people leading an active lifestyle, physicians and society at large tend to view obese patients negatively; if weight loss treatment fails, they tend to blame the patient. ${ }^{3}$ Therefore, obesity must be adequately addressed in medical school. Here, I will review how obesity education is implemented in the medical education curriculum in Korea.

\section{OBESITY EDUCATION AND ATTITUDES TOWARD OBESE PATIENTS}

In 1999-2000, a survey of medical students at the University of South Florida found that obesity was only covered in their bariatric surgery rotation. Because obesity was not recognized as a disease, obesity education at medical school was not properly performed at 
that time. ${ }^{4}$ A paper in 2012 reported that the medical school at Bond University surveyed first- through fourth-year students for 3 consecutive years; despite growing medical knowledge, about $60 \%$ of them did not consider obesity a disease. ${ }^{5}$ According to a previous study, when U.S. medical students who had not yet received proper obesity education met virtually with an obese patient and a non-obese patient, they showed negative attitudes, beliefs, and other interpersonal behaviors based only on the patient's obesity. ${ }^{6}$ Similar results were obtained from studies conducted at medical schools in Germany ${ }^{7}$ and Mexico. ${ }^{8}$ This demonstrates that the concept of obesity as a disease should be properly presented to medical students. There are also studies on how to measure the attitudes and beliefs of medical students about obese patients. The Nutrition, Exercise, and Weight Management (NEW) Attitude Scale (Table 1 ) is a useful tool, with a test-retest reliability of 0.89 , suggesting that it easily assesses changes in attitude toward obese patients after presenting lessons. ${ }^{9}$

\section{PLAY-READING}

Matharu et al..$^{10}$ have used play-reading methods to reduce prejudice of medical students toward obese patients. The subjects were randomly assigned to a lecture group or a play-reading group. The lecture group received a 1-hour lecture about medical management of obesity, which included an account of a patient experiencing prejudice from society and a health care provider and emphasized the importance of patient motivation for successful treatment. After the lecture, they had a question and answer session. The playreading group read the 1-hour script of The Most Massive Woman Wins by Madeleine George. It is an autobiographical essay on how a woman has come to understand her body weight in diverse lives and social discrimination. The students who read the script, the students in the audience, and the readers were asked to discuss it together. Empathy for obese patients increased after both lecture and play-reading, but there was no difference between the two groups because their empathy ability was already high. On the other hand, explicit bias decreased significantly in the play-reading group compared to the lecture group. Therefore, the authors ${ }^{10}$ suggest that it is necessary to combine traditional lectures with pedagogical methods that allow students to reflect on themselves, such
Table 1. Nutrition, Exercise, and Weight Management (NEW) Attitude Scale items

\section{Key contents}

1. There is no excuse for a patient to be overweight/obese.

2. It is usually sufficient to give a person brief, clear advice about weight management.

3. People can eat a healthy diet if they choose to do so.

4. Counseling about nutrition does not change behavior.

5. I believe if I eat a healthy diet, it would make me an effective role model.

6. I find it rewarding to talk to someone about nutrition.

7. I have a personal desire to counsel patients about nutrition.

8. Patients understand the connection between nutrition and cancer.

9. American food culture contributes to the overweight/obese problem.

10. Patients are likely to follow an agreed upon plan to increase their exercise

11. Even if I counsel them, patients will continue their poor exercise habits.

12. I have a personal desire to counsel patients about exercise.

13. Overweight individuals tend to be lazy about exercise.

14. Patients understand the connection between exercise and cancer.

15. Patients think lack of exercise can be a serious health risk.

16. I believe patients can maintain weight loss.

17. I think obese patients are motivated to change their lifestyle.

18. I feel effective in helping overweight/obese patients manage their weight.

19. I believe that my patients will follow through with a weight management program.

20. I feel confident treating overweight/obese patients.

21. I think treating overweight/obese patients is not worth the time.

22. Weight management counseling takes too much time.

23. I do feel a bit disgusted when treating a patient who is obese.

24. If a patient is overweight/obese, I feel awkward discussing his/her weight.

25. The person and not the weight is the focus of weight management counseling.

26. Patients know the health risks related to their weight.

27. Patients take their weight seriously.

28. Patients understand the connection between weight and cancer.

29. I have a personal desire to counsel patients about weight management.

30. Overweight/obese individuals lack will power.

31. Patients think being overweight/obese is a serious health risk.

as play-reading, in order to reduce medical students' prejudice toward obesity.

\section{USING STANDARDIZED PATIENTS}

In a previous study ${ }^{11}$, the first-year medical students of Northwestern University Feinberg School of Medicine were asked to read two papers related to communication and stigma and then to counsel standardized patients on their overweight status and perception of becoming increasingly overweight. Six scenarios were created for obesity counseling. After 8 minutes of student counseling, the student received feedback for another 8 minutes. First, the 
student stated what he did well, and fellow students commented, followed by comments from the standardized patient. Stereotypes and empathy for obese patients after the standardized patient class increased slightly compared to before the class, and confidence in counseling obese patients increased significantly. After 1 year, stereotypes returned to pretraining levels, but empathy and confidence in obesity counseling remained elevated. Authors ${ }^{11}$ argued that these lessons using standardized patients were effective in improving students' ability to counsel obese patients.

\section{DEVELOPING OR DELIVERING OBESITY EDUCATION PROGRAMS}

McAndrew et al. ${ }^{12}$ asked first-year medical students at the Medical College of Wisconsin to develop an education program for adolescents about the effects of obesity on health. Twenty-five medical students were trained for 2 years, and they educated 1,590 adolescent students. As a result, medical students improved communication skills with adolescents and gained experience as future doctors. Similarly, students at the Medical University of South Carolina provided a 10-week, free, weight-management intervention for obese low-income residents around the school as an extracurricular course. After completing the course, the participating students were prepared to provide obesity treatment and became interested in what physicians should provide to community members. ${ }^{13}$

\section{PARTICIPATION IN WEIGHT LOSS PROGRAMS}

The Department of Family Medicine, East Carolina University offered third-year clerkship students 4 weeks of individual weight management experience. Additional credits were awarded to students who completed the program. Students were asked to review a paper on weight loss strategies and to assess their current height, weight, body mass index, and waist circumference. Then, students were asked to design a diet and exercise plan by calculating the calorie intake per day according to the rest energy amount. Students monitored their condition while writing a daily diary. Four weeks later, students measured their bodies again. The participating students were able to see the direct impact of these programs on their health and to better understand obese patients. ${ }^{14}$

\section{PAIRING STUDENTS WITH OBESE PATIENTS UNDERGOING BARIATRIC SURGERY}

At the Beth Israel Deaconess Medical Center, Harvard Medical School, four third-year medical students were matched with obese patients undergoing obesity surgery, and nine students were followed for 1 year as controls. Each student paired with an obese patient had a long-term relationship with the patient and participated in the entire management course of the patient for 1 year before surgery. As a result, these students' attitudes toward obesity and understanding of obesity and bariatric surgery changed compared to before the program. ${ }^{15}$

\section{CONCLUSION}

Obesity education includes diverse fields such as diet, nutrition, exercise, behavior therapy, and medication; thus, if medical students understand obesity well, they can apply their knowledge to other diseases. Adequate nutrition is essential for disease prevention and treatment, but it is not easy for physicians to provide nutritional counseling. This is probably due to a lack of basic knowledge of nutrition and applied clinical experience from medical school and resident training programs. Indeed, over the last decade, most U.S. medical school curricula have shown a lack of adequate nutrition education for medical students. According to a report from the National Academy of Sciences in 1985, nutrition education in the 4-year curriculum totaled only 21 hours although at least 25 hours of education were required to allow for patient nutrition considerations. In 2008-2009, when the survey was conducted again, nutrition education had been reduced to 19.6 hours during the 4-year curriculum. ${ }^{16}$ There are many other topics that medical students should be taught, so there is resistance to introducing new courses or lengthening existing ones; in fact, the content taught is more important than the amount of time spent.

Unfortunately, Korea is not yet aware of the current status of obesity education in medical education. Therefore, it is necessary to refer to improvement efforts of medical schools and obesity-re- 
lated organizations in other countries. The best example is a core curriculum of nutrition needed for medical students, developed by nutrition specialists and made available for free in the U.S. as well as abroad. The curriculum divides core education topics into nutrition basics, nutritional evaluation, prevention, disease treatment, and nutrition; and these subjects are grouped broadly into the titles of disease, life cycle, and special topics. Although all the content is included in a single course, each school can distribute the topics into various related courses as needed. The KSSO is more interdisciplinary than any other society because it includes experts from various fields such as basic research, clinical practice, nutrition, nursing, exercise, and rehabilitation. The group is thus well equipped to identify the core competencies of obesity education necessary for medical students, design concrete curricula of obesity education, and present examples of lectures and discussions. In the future, health professionals who receive such education will be able to take better care of obese patients without bias.

\section{CONFLICTS OF INTEREST}

The author declares no conflict of interest.

\section{REFERENCES}

1. Kim YH, Han K, Son JW, Lee SS, Oh SW, Kwon HS, et al. Data analytic process of a nationwide population-based study on obesity using the National Health Information Database presented by the National Health Insurance Service 20062015. J Obes Metab Syndr 2017;26:23-7.

2. Kim MK, Lee WY, Kang JH, Kang JH, Kim BT, Kim SM, et al. 2014 Clinical practice guidelines for overweight and obesity in Korea. Endocrinol Metab (Seoul) 2014;29:405-9.

3. Puhl R, Suh Y. Health consequences of weight stigma: implications for obesity prevention and treatment. Curr Obes Rep 2015;4:182-90.

4. Banasiak M, Murr MM. Medical school curricula do not address obesity as a disease. Obes Surg 2001;11:677-9.

5. Erueti C, Glasziou P, Mar CD, van Driel ML. Do you think it's a disease? A survey of medical students. BMC Med Educ
2012;12:19.

6. Persky S, Eccleston CP. Medical student bias and care recommendations for an obese versus non-obese virtual patient. Int J Obes (Lond) 2011;35:728-35.

7. Pantenburg B, Sikorski C, Luppa M, Schomerus G, König $\mathrm{HH}$, Werner $\mathrm{P}$, et al. Medical students' attitudes towards overweight and obesity. PLoS One 2012;7:e48113.

8. Soto L, Armendariz-Anguiano AL, Bacardí-Gascón M, Jiménez Cruz A. Beliefs, attitudes and phobias among Mexican medical and psychology students towards people with obesity. Nutr Hosp 2014;30:37-41.

9. Ip EH, Marshall S, Vitolins M, Crandall SJ, Davis S, Miller D, et al. Measuring medical student attitudes and beliefs regarding patients who are obese. Acad Med 2013;88:282-9.

10. Matharu K, Shapiro JF, Hammer RR, Kravitz RL, Wilson $\mathrm{MD}$, Fitzgerald FT. Reducing obesity prejudice in medical education. Educ Health (Abingdon) 2014;27:231-7.

11. Kushner RF, Zeiss DM, Feinglass JM, Yelen M. An obesity educational intervention for medical students addressing weight bias and communication skills using standardized patients. BMC Med Educ 2014;14:53.

12. McAndrew S, Jackman C, Sisto PP. Medical student-developed obesity education program uses modified team-based learning to motivate adolescents. Med Teach 2012;34:414-6.

13. Brown J, Lydecker JA, Turner T, Knackstedt RW, O'Neil PM. A novel approach to training students in delivering evidencebased obesity treatment. Fam Med 2015;47:378-82.

14. Schmidt S, Rice A, Kolasa K. Teaching by example: educating medical students through a weight management experience. Fam Med 2013;45:572-5.

15. Roberts DH, Kane EM, Jones DB, Almeida JM, Bell SK, Weinstein AR, et al. Teaching medical students about obesity: a pilot program to address an unmet need through longitudinal relationships with bariatric surgery patients. Surg Innov 2011;18:176-83.

16. Adams KM, Kohlmeier M, Powell M, Zeisel SH. Nutrition in medicine: nutrition education for medical students and residents. Nutr Clin Pract 2010;25:471-80. 